\title{
Avaliação de Agrotóxicos em Água para Consumo Humano - Estratégias Analíticas para o Monitoramento e Aspectos Regulatórios
}

\author{
Ivy S. Palmeira, Amanda I. S. F. Ginuino, Tatyane P. Santos \\ \& Ana C.S. Rosa
}

\begin{abstract}
Este trabalho tem por finalidade ampliar a capacidade de avaliação dos agrotóxicos em água para consumo humano, otimizar estratégias analíticas para o monitoramento e propor mudanças na legislação federal brasileira. Foi feito um levantamento de quais agrotóxicos são utilizados nos municípios brasileiros e dos 511 compostos autorizados para uso pela ANVISA, foram selecionados 170 agrotóxicos, que estão sendo inseridos na nova metodologia analítica. Espera-se que para a análise multiresidual de agrotóxicos de características físico-químicas diversas, sejam utilizadas as técnicas de cromatografia gasosa e líquida, ambas hifenadas a espectrometria de massas com triplo quadrupolo.
\end{abstract}

Palavras Chave: Agrotóxicos; Água; Consumo Humano.

AbstractThis work' objective is to increase the pesticide evaluation in drinking water for human consumption, optimize analytical methods for monitoring and propose changes in Brazilian federal legislation. A survey was carried out of which pesticides are used in Brazilian municipalities and from 511 compounds authorized for use by ANVISA, 170 pesticides were selected, which are being inserted in the new analytical methodology. It is expected that through multiresidual analysis of different pesticides with various physico-chemical characteristics, gas and liquid chromatography will be used, both coupled to triple quadrupole mass spectrometry.

Keywords: Pesticides; Water; Human Consumption. 


\section{Introdução}

Os agrotóxicos representam um importante problema para a saúde humana e ambiental porque são substâncias, na maioria das vezes, com elevado nível de toxicidade e de uso massivo tanto no meio urbano, onde são usados em campanhas de saúde pública, por empresas de desinsetização, ou no próprio ambiente doméstico para o combate a insetos, quanto no meio rural, onde os agricultores os utilizam sem muitos cuidados com as misturas e quantidades aplicadas, que são fatores essenciais durante sua manipulação (WORLD HEALTH ORGANIZATION, 2016).

O aumento do uso de agrotóxicos vem ocorrendo em quase todo mundo, sendo possível fazer sua estimativa através da Organização das Nações Unidas para Alimentação e Agricultura, pela avaliação para cada país (FOOD AND AGRICULTURE ORGANIZATION, 2013). O consumo mundial teve sua distribuição de $45 \%$ para toda a Europa, $25 \%$ para os EUA e $25 \%$ para o restante do mundo, sendo o dado anterior ao ano da publicação (DE et al., 2014).

A utilização de agrotóxicos no Brasil tem sido foco de preocupação em diversos segmentos da nossa sociedade. $\mathrm{O}$ cidadão comum, o meio científico e as instituições governamentais vêm sendo alertados ou têm alertado sobre os impactos à saúde humana e ambiental que essas substâncias podem causar. Ano a ano o Brasil supera seus recordes de comercialização e uso de agrotóxicos. Desde 2008 o Brasil tem sido o maior consumidor de agrotóxicos do mundo, ficando à frente de países como os Estados Unidos e China (CARNEIRO; ABRASCO, 2015).

Atualmente existem 511 monografias autorizadas de produtos registrados no Brasil usados como ingredientes ativos destinados ao uso agrícola, saneantes desinfestantes, não agrícola, ambientes aquáticos e preservante de madeira. Destes, 350 contribuem com 98\% das formulações de agrotóxicos mais utilizados, sendo que $80 \%$ deles são rotineiramente usados na agricultura do Brasil (ANVISA, 2016a).

Os três inseticidas mais utilizados no país no ano de 2014, e suas respectivas classes toxicológicas, foram acefato (classe III), clorpirifós (classe II), metomil (classe
I), sendo acefato e clorpirifós da classe química dos organofosforados, correspondendo a 42.000 toneladas de princípio ativo (IBAMA, 2016).

Considerando outros ainda que extrapolam esta lista, são usados carbamatos, triazinas, organofosforados, piretróides, derivados de uréia, bipiridílicos e nitrocompostos, e a maioria deles podem causar riscos à saúde humana e ao meio ambiente. O glifosato também vem sendo apontado como o herbicida mais utilizado no país atualmente.

Visando a garantia da qualidade das águas, os Ministérios da Saúde e Meio Ambiente determinam valores máximos permitidos (VMP) para agrotóxicos em águas destinadas ao consumo humano, uma vez que o controle da poluição está diretamente relacionado com a proteção da saúde, garantia do meio ambiente ecologicamente equilibrado e a melhoria da qualidade de vida. O Anexo XX da Portaria de Consolidação $\mathrm{n}^{\mathrm{o}}$ 5, de 03/10/2017, do Ministério da Saúde, antiga Portaria n. ${ }^{0} 2914$ do Ministério da Saúde de 2011, define o padrão de potabilidade da água para consumo humano, fornecendo VMP para 38 agrotóxicos. A resolução do Conselho Nacional do Meio Ambiente (CONAMA, 2005) n ${ }^{\circ} 357$, de março de 2005, determina a classificação das águas doces destinadas, após tratamento específico, ao abastecimento para consumo humano como águas de classe 1, classe 2 e classe 3, definindo VMP para 25 agrotóxicos nas águas de classe 1 e 2 e para 20 agrotóxicos nas águas de classe 3 .

\section{Metodologia}

Aumentar o escopo do método analítico para incluir agrotóxicos mais utilizados no país, segundo dados fornecidos pelos municípios agrícolas, IBAMA e regulações estaduais mais restritivas que a federal.

Analisar os VMP de agrotóxicos no Anexo XX e na Resolução CONAMA 357 quanto à concordância com o número de ingredientes ativos e classes químicas mais utilizadas atualmente na agricultura; demandas de uso regionais.

\section{Resultados e Discussão}

Tanto o Anexo XX, quanto a Resolução CONAMA 357 
apresentam limitações quanto ao número de agrotóxicos analisados, que é muito inferior ao número de ingredientes ativos disponíveis para o preparo de formulações comerciais.

Os inseticidas da classe dos organofosforados (OPs), carbamatos e piretróides, não foram amplamente abrangidos. Esta recomendação não consta no CONAMA 357, que prevê VMP para apenas 4 OPs e 1 carbamato. VMP para piretroides são previstos apenas na Portaria 2914 e somente para um composto. Os grupos químicos de grande toxicidade a saúde também necessitam de maior abrangência, como é o caso dos OPs, acima citados. Não há referências a observância das demandas de uso regional, uma carência, pois a escolha do agrotóxico depende de diversos fatores, que vão desde a cultura plantada até costumes locais.

Conclusões

Há a demanda de uma revisão das leis brasileiras no que tange a qualidade das águas, de modo a contemplar a imensa variedade de agrotóxicos, as diferenças de demandas de uso regionais e as propriedades cumulativas e tóxicas destes compostos. É necessário também rever os VMP de alguns compostos, que são demasiadamente altos, podendo colocar em risco a saúde da população, além da necessidade eminente de se determinar VMP que previna os riscos decorrentes de uma exposição ambiental que é caracterizada por múltiplas fontes.

\section{Agradecimentos}

Ao Ministério da Saúde pelo suporte.

\section{Referências Bibliográficas}

1. ANVISA. Monografias Autorizadas de Agrotóxicos, 2016. Acesso em: 10 abr. 2016

2. CARNEIRO, F. F.; ABRASCO (EDS.). Dossiê ABRASCO: um alerta sobre os impactos dos agrotóxicos na saúde. Rio de Janeiro : São Paulo: Escola Politécnica de Saúde Joaquim Venâncio ; Expressão Popular, 2015.

3. CONAMA. Resolução 357. Dispõe sobre a classificação dos corpos de água e diretrizes ambientais para o seu enquadramento, bem como estabelece as condições e padrões de lançamento de efluentes, e dá outras providências. 17 mar. 2005, p. 58-63.

4. DE, A. et al. Worldwide Pesticide Use. In: DE, A. et al. (Eds.). . Targeted Delivery of Pesticides Using Biodegradable Polymeric Nanoparticles. New Delhi: Springer India, 2014. p. 5-6.

5. Food and Agriculture Organization. Disponível em: $<$ http://faostat. fao.org/site/424/default.aspx\#ancor> . Acesso em: 19 set. 2016.

6. IBAMA. Boletim anual de produção, importação, exportação e vendas de agrotóxicos no Brasil - 2014. Brasília, DF: IBAMA, MMA, 2016.

7. Instituto de Economia Agrícola. Análises e Indicadores do Agronegócio. Defensivos agrícolas: em 2014, faturamento do segmento foi o destaque, v. 10, p. número 5, 2015.

8. World Health Organization. Disponível em: $<$ http://www.who.int/ topics/pesticides/en/>. Acesso em: 19 set. 2016.

\section{Ivy S. Palmeira*, Amanda I. S. F. Ginuino, Tatyane P. Santos \& Ana C.S. Rosa}

Escola Nacional de Saúde Pública, Fundação Oswaldo Cruz, Rua Leopoldo Bulhões, 1480, Manguinhos, Rio de Janeiro - RJ, 21041-210

*E-mail: ivydesouza14@gmail.com 